\title{
A Química rumo ao futuro: dispositivos e máquinas moleculares*
}

V I N C E N Z O B A L Z A N I**

Ao iniciar este discurso inaugural, o meu pensamento recua nos séculos a quando, contam-se já mais de novecentos anos, na nossa cidade a paixão pelo saber levou ao primeiro esboço da instituição que hoje conhecemos pelo nome de Universidade. E a minha gratidão vai para a longa fila de cientistas que deram fama ao nosso ateneu e que nos abriram o caminho da ciência. Como químico, recordo (Figura 1) Jacopo Bartolomeo Beccari, para o qual em 1737 foi instituída, primeira em Itália, a Cátedra de Química, e Giacomo Ciamician que, na sua memorável lição na abertura do ano académico 1903-1904 sobre o tema "I problemi chimici del nuovo secolo", soube não só fascinar o seu auditório, como também transmitir intuições que ainda hoje nos maravilham. Sem pretensões de conseguir imitar um tal Mestre, tentarei fazer um discurso que seja compreensível e, espero, interessante para muitos.

Aceitei com prazer o convite que me foi dirigido pelo Magnífico Reitor, porque pensei que esta lição inaugural pudesse ser uma ocasião preciosa para melhor fazer conhecer a Química e para reflectir sobre o papel que a Química e, de uma forma mais geral a Ciência, desempenham na nossa civilização.

\section{AVERSÃO À CIÊNCIA E EM PARTICULAR À QUÍMICA}

Um amigo disse-me que foi um acto de coragem, mas talvez quisesse dizer temeridade, colocar a palavra "química" no título desta lição. A química, de facto, tem actualmente uma imagem completamente negativa. Num artigo saído há algum tempo na revista Airone, o cientista e senador Giorgio Nebbia perguntava-se inclusivé se "química" não se teria já transformado num palavrão, dado que se encontra sempre associada a adulteração, acidentes e poluição. De facto, quando troco meia dúzia de palavras no elevador ou no comboio com uma pessoa antes não conhecida, logo que digo ser um professor de

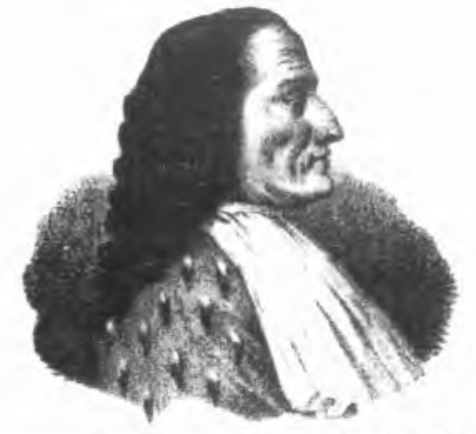

Jacopo Bartolomeo Beccari (1737-1757)

química, noto no meu interlocutor, uma brusca diminuição de interesse e também um certo sentimento de surpresa. Penso que no seu íntimo se interrogue como é que uma pessoa como eu, aparentemente normal, possa rebaixar-se a ensinar à rapaziada uma coisa tão absurda e pouco limpa como a química. Este fenómeno não é somente italiano. De tal forma que, uma prestigiosa revista científica americana, meio a sério meio a brincar, publicou um curso de química com a duração de um só minuto para que os químicos, num elevador ou durante outros breves encontros, possam explicar correctamente às pessoas o que é a química $\mathrm{e}$ porque é a química importante.

Na realidade nos dias de hoje não só a química, mas toda a ciência apresenta uma imagem muito negativa. Este clima anti-científico é bem ilustrado pelo título de um artigo saído recentemente num conhecido quotidiano: "Vade retro progresso, a América tem medo: na pátria da tecnologia, já ninguém acredita nas suas virtudes."

No nosso País'1), além de uma substancial desconfiança em relação à ciência, está instalado o preconceito de que a verdadeira cultura é apenas a humanística. São numerosas as pessoas cultas que quase se orgulham de não perceber nada de matemática, de física e de química. É convicção generalizada, sobretudo em âmbito escolar, que as disciplinas literárias sejam mais formativas do que as científicas. Conceito que não corresponde à realidade, como foi sublinhado pelo filósofo Paolo Rossi

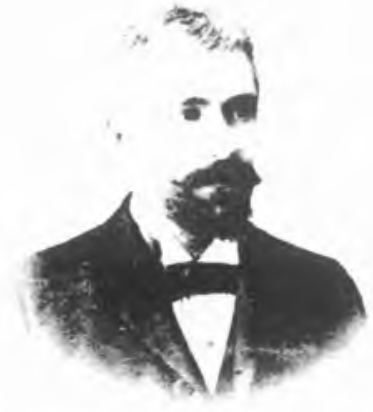

Giacomo Ciamician (1889-1922)

Monti numa entrevista recente na qual dizia, por exemplo, que não fazer uma ideia do quer dizer "princípio da inércia" é tão grave como nunca ter lido Shakespeare. A ignorância científica é verdadeiramente colossal. De acordo com um inquérito recente, $12 \%$ dos cidadãos europeus está convencido, 4 séculos após Galileo, que o Sol gira à volta da terra. O facto é preocupante, porque uma pessoa cientificamente analfabeta nunca poderá ser um bom cidadão. Na altura das escolhas de política científico-tecnológica, que se apresentam cada vez com maior frequência, quem não tem educação científica ver-se-á obrigado a confiar no entender dos peritos na matéria, correndo o risco de os ver transformados em ditadores.

Nos dias que correm, a opinião dominante, até em pessoas de uma certa cultura, é que a química, para além de ser uma matéria escolar abstrusa, é algo de que é melhor manter-se afastado porque identificada com adulteração e poluição. Na publicidade ao presunto de Parma, que apareceu nos principais jornais, escreve-se em letras grandes que nele, no tal presunto, não existe nada de químico. A realidade, bem pelo contrário, é que naquele presunto tudo é químico. De anúncios como este e de tantas outras notícias insensatas que chegam da imprensa e da televisão, o cidadão comum é levado a pensar que "químico" seja o oposto de "natural" e que a química seja algo que provavelmente se poderia, e em todo o caso se deveria, dispensar. Uma proposta de referendo para 
abolir a química recolheria hoje facilmente as necessárias 500000 assinaturas. Eu gostaria muito que alguém propusesse esse referendo. Seria finalmente chegada a ocasião certa para explicar às pessoas que a química não se pode eliminar, pelo simples facto que se encontra em tudo o que nos rodeia e em nós. Está à nossa volta nos fenómenos naturais indispensáveis à vida, como a fotossíntese, e nos produtos artificiais de importância primária para a nossa civilização, como os fármacos, os fertilizantes, as matérias plásticas. Está em nós porque o homem "funciona" ou "não funciona" através de reacções químicas. A concepção, o crescimento e a morte são processos químicos, ainda que muito complexos. Até aqueles que chamamos processos mentais (a aprendizagem, a memória, o pensamento, a experiência, os sonhos) são o resultado de intrincados processos químicos que se desenrolam no nosso cérebro. Portanto, abolir a química quereria dizer não só abolir as adulterações alimentares e poluição, mas também abolir os combustíveis, os fármacos, os fertilizantes, as matérias plásticas, os semicondutores, os detergentes, ou seja, todos os benefícios que, dum modo quase inconsciente, usufruímos todos os dias; e quereria também dizer abolir as plantas, os animais, e o próprio homem. Quereria dizer abolir tudo, porque tudo, até o presunto de Parma, é química.

É pois necessário não confundir a química com os efeitos maléficos que produz quando mal utilizada. Claro, com um produto químico chamado fármaco pode salvar-se uma vida, e com um outro produto químico chamado veneno pode ceifar-se uma vida. Mas também com uma faca se pode cortar o pão ou matar um homem. E nenhuma pessoa sensata, no segundo caso, daria a culpa à faca.

\section{ÁTOMOS E MOLÉCULAS}

A química explica-nos o "porquê" e o "como" da vida de todos os

dias. Explica-nos, por exemplo, porque é que os alimentos se conservam por mais tempo no frigorífico, como consegue a nossa boca distinguir o açúcar do sal, porque é que o monóxido de carbono é venenoso, como funciona a fotossíntese nas plantas. Explica-nos tudo isto partindo das propriedades dos átomos e das moléculas.

De facto, por exemplo, para perceber como "funciona" uma árvore, é necessário baixar, bem baixo até ao pequeno, como num "zoom" (Figura 2 ), ir da árvore às folhas, às células, aos cloroplastos, aos grânulos, às membranas, até conseguir ver o que sucede ao nível molecular. As moléculas são objectos muito pequenos. Dez biliões de vezes mais pequenas que os objectos que nos rodeiam na vida de todos os dias. A unidade de medida das moléculas é o nanómetro, $10^{-9}$ metros, um bilionésimo de metro. É difícil darmo-nos conta de como são pequenas as moléculas. Se disser que numa gota de água se encontram $10^{21}$ moléculas, podem-me perguntar o que significa $10^{21}$. Pergunta pertinente pelo facto que os números muito grandes ou muito pequenos não se podem conceber senão através de comparações adequadas. Eis então: se pudéssemos distribuir as moléculas existentes numa gota de água por todos os homens da terra, caberiam cerca de 200 biliões a cada um. Ou então, se contássemos as moléculas que existem numa gota

Árvore

Folhas (comprimento) (espessura)

Células

Cloroplastos

Grânulos

Membranas (espessura)

Moléculas
$10 \mathrm{~m}$

$10 \mathrm{~cm}$

$0.3 \mathrm{~mm}$

$50 \mathrm{~mm}$

$5 \mathrm{~mm}$

$200 \mathrm{~nm}$

$2 \mathrm{~nm}$

$0.5 \mathrm{~nm}$ de água ao ritmo de 1 ao segundo, necessitaríamos de trinta mil biliões de anos para as contar todas.

Mas para melhor se fazer uma ideia do que sejam os átomos e as moléculas e do que globalmente seja a química, pode-se recorrer a uma analogia entre química e linguagem.

Qualquer linguagem se baseia em letras, duas dezenas na língua italiana (a, b, c, etc.), organizadas num alfabeto. As letras da química são os átomos (hidrogénio, H; oxigénio, O; carbono, C, etc., cerca de uma centena) e o alfabeto da química é a tabela periódica (que até os literatos conhecem, graças ao livro homónimo de Primo Levi ${ }^{21}$. Sabemos todos que as letras do alfabeto se podem combinar em grupos, segundo uma lógica inventada pelo homem: obtêm-se, assim, as palavras. Algo de semelhante acontece com os átomos. Agrupando os átomos segundo as regras impostas pela natureza, obtêm-se as moléculas, que são pois as palavras da química. Assim como existem palavras compridas e palavras curtas, também existem moléculas constituídas por poucos átomos (como a molécula de água, que tem dois átomos de hidrogénio e um de oxigénio) e outras muito grandes (como a hemoglobina que tem 9072 átomos). Uma primeira conclusão a que se pode chegar, é a de que assim como a linguagem é feita de palavras, assim o mundo é feito de moléculas.

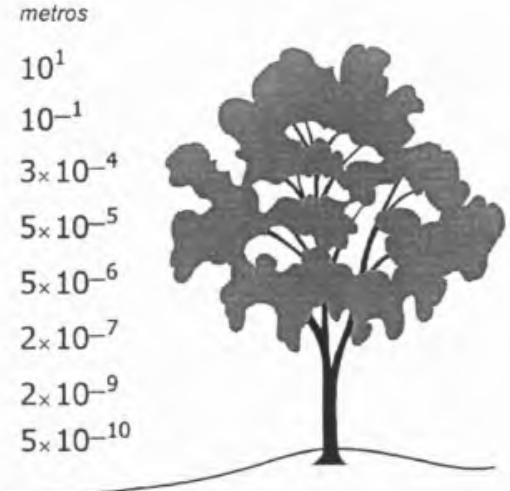


Com uma só palavra não é possível exprimir um conceito. Na linguagem, portanto, as palavras são agrupadas, segundo certas regras, em frases. Algo de semelhante sucede na química: uma molécula não é suficiente para executar uma função. Algo que, no entanto, é possível de obter através de sistemas compostos por mais de uma molécula, as chamadas supermoléculas.

Continuando com esta comparação, em modo muito grosseiro e quase por brincadeira, poder-se-á passar a sistemas mais complexos (Figura 3), e portanto comparar um parágrafo a um enzima, um capítulo de um livro a uma mitocôndria, um livro a um protozoário, uma colecção de livros a um animal pouco evoluído e, enfim, uma inteira biblioteca a um homem. Chegados a este ponto podemos questionarmo-nos: existem mais letras numa biblioteca ou átomos num homem? Tomemos a biblioteca inaugurada em Paris alguns anos atrás, que é talvez a maior do mundo. Contém cerca de 10 milhões de volumes, para um total de $10^{13}$ letras (ou seja, dez mil biliões de letras). O número de átomos contidos no corpo de um homem é da ordem de $10^{27}$, cem mil biliões de vezes maior que o número de letras existente na biblioteca de Paris. Portanto, a comparação biblioteca-homem é sem dúvida irrelevante para o homem, até no plano simplesmente quantitativo, já que o número de átomos contidos no corpo de um homem é igual ao número de letras que se encontram em cem mil biliōes de bibliotecas. E assim como as letras contidas numa biblioteca não se encontram dispostas ao acaso, mas organizam-se em palavras, frases, parágrafos, capítulos, volumes e colecções, com o fim de exprimir informações e conceitos, também os átomos do corpo humano estão bem ordenados em moléculas, sistemas supramoleculares, células e orgãos para executarem as funções necessárias à vida.

Esta analogia entre química e linguagem, ainda que limitada, tem o dom de nos permitir compreender que as moléculas são as palavras da

\section{LIN G UA G E M}

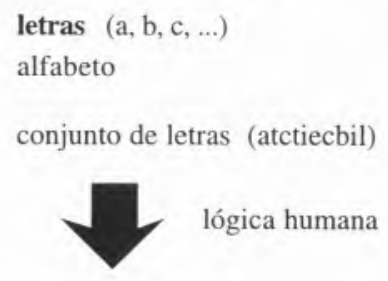

palavras (bicicleta)
frases
parágrafos
capítulos de um livro
livros
colecções de livros
bibliotecas

molécula (glicina, $\mathrm{NH}_{2} \mathrm{CH}_{2} \mathrm{COOH}$ )

supermoléculas simples (membranas) supermoléculas complexas (enzimas) organelos intracelulares (mitocôndrias) organismos unicelulares (protozoários) organismos pluricelulares simples (moluscos) organismos pluricelulares complexos (homem) química e que os organismos vivos são sistemas químicos constituídos por um íncrível número de moléculas, todas dispostas num modo igualmente incrivelmentente ordenado.

Por conseguinte, os átomos e as moléculas constituem os tijolos de tudo aquilo que nos rodeia e do nosso próprio corpo. Os átomos e as moléculas de que somos feitos encontram-se numa troca permanente com o ambiente que nos rodeia através de reacções químicas. Todos os dias ao respirar, comer, beber, retiramos do ambiente biliões e biliões de átomos e devolvemos ao ambiente aproximadamente igual quantidade suando, respirando, eliminando dejectos. Será pouco poético, mas cada nosso respirar tira e repõe em circulação biliões e biliões de átomos já reciclados nas últimas semanas pela respiração de outros seres vivos. Tudo em nós é continuamente regenerado, vindo da matéria e da energia do ambiente que nos rodeia. A nossa pele é renovada todos os meses, o nosso fígado de seis em seis semanas. Todos os anos $98 \%$ do nosso corpo é regenerado. Podemos afirmar que, de tudo aquilo que vive sobre a terra, somos o mais reciclado. Por fim até as nossas recordações, que são estruturas especiais no nosso cérebro, são continuamente desmontadas e remontadas através desta substituição atómica e molecular.
Chegados a este ponto, podemos interrogarmo-nos sobre outros "como" e "porquê": porque é que estamos no mundo? apenas para reciclar átomos e moléculas, ou a nossa vida tem um valor transcendente? quem escolheu as leis que governam os fenómenos que observamos? que significado tem a vida do homem, único sujeito num mundo de objectos? como se explica que o homem, cujo coração é constituído por átomos como o é uma pedra, possua a faculdade de amar e perdoar? Segundo o famoso zoólogo da universidade de Oxford, Richard Dawkins, só quem não possui educação científica pode colocar estas questões. Eu não partilho da opinião de Dawkins. Eu penso que estas questões interpelam o cientista ainda mais profundamente que a gente comum, precisamente porque o cientista sabe que a estas perguntas a ciência não pode dar resposta.

\section{O MODERNO PAPEL DA QUÍMICA: ENGENHARIA MOLECULAR}

Mas voltemos à química. Por muito tempo, o químico foi essencialmente um explorador da natureza. A sua tarefa era a de descobrir a composição e estrutura dos produtos naturais e compreender quais as regras que a natureza impõe aos fenómenos 
químicos. A situação foi-se modificando pouco a pouco, por duas razões: em primeiro lugar a operação "conhecimento da natureza" encontra-se muito avançada; em segundo lugar, o químico, desvendando os segredos dos processos naturais, deu-se conta de possuir a capacidade de sintetizar compostos e de meter em acção processos que não existem na natureza e que consequentemente vêm apelidados de artificiais. Ao lado do químico explorador da natureza encontra-se sempre mais frequentemente o químico inventor, o químico engenheiro a nível atómico e molecular. Ao grande número de moléculas existentes na natureza, os químicos acrescentaram cerca de 15 milhões de novas moléculas.

É já possível preparar moléculas de qualquer forma e dimensão. Alguns exemplos encontram-se esquematicamente representados na Figura 4: moléculas em forma de árvore, de ponte, de corrente, de bola de futebol. Acontece pois na química o admiravelmente descrito numa frase de Leonardo: "Onde a natureza finda de produzir as suas espécies, começa o homem, em harmonia com as leis da natureza, a criar uma infinidade de espécies".

Sintetizar uma nova molécula, um novo material, é um acto criativo complexo que exige ideias, organização, trabalho. Como qualquer acto criativo, tem os seus riscos. Isto é bem sabido, mas também é sabido como se deve proceder para evitá-los. Hoje, por exemplo, qualquer potencial novo fármaco, antes de ser utilizado, é submetido a muitos anos de experimentação para verificar a ausência de efeitos negativos. Claro que se pode errar, como em qualquer outra actividade humana. Mas o balanço da química em relação à humanidade é muito positivo. Com os fertilizantes podemos aumentar as colheitas, com os remédios combatemos as doenças, com os analgésicos eliminamos a dor. com os combustíveis diminuimos o esforço manual, com as fibras artificiais protegemo-nos do frio e da chuva. E poderia continuar com muitos outros exemplos.
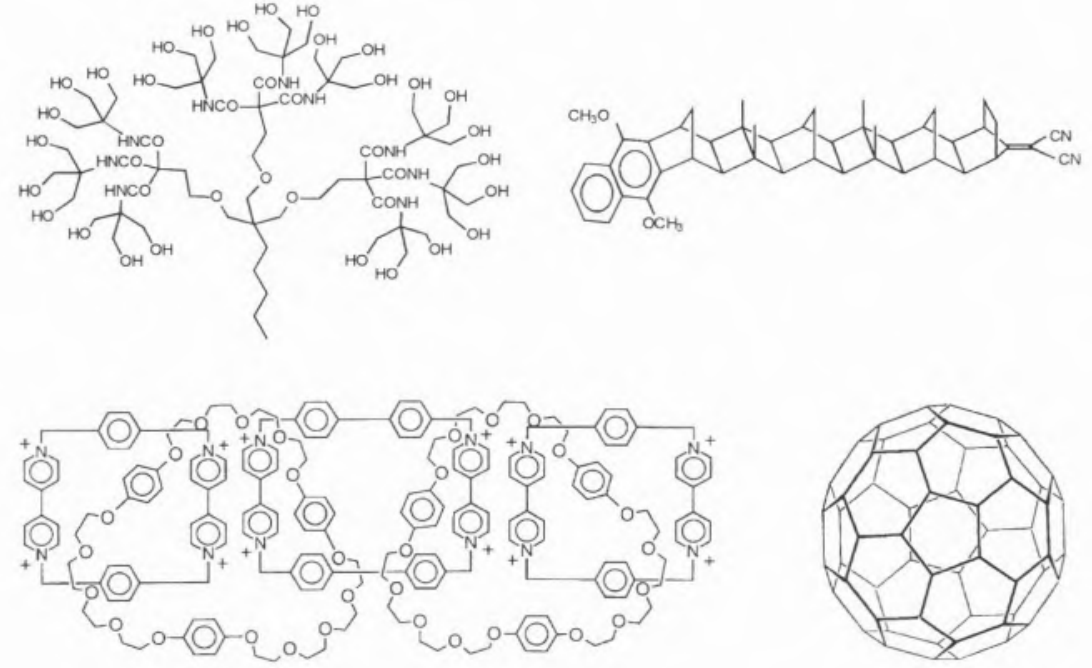

Figura 4

\section{A QUÍMICA DO FUTURO E A NANOTECNOLOGIA}

Nos próximos anos a química produzirá por certo, fármacos mais eficazes, materiais mais ligeiros e resistentes, métodos de análise mais sensíveis. Mas trar-nos-á também muitas surpresas. As maiores expectativas dizem respeito ao campo da nanotecnologia, que significa tecnologia ao nível do nanómetro (bilionésimo de metro), ou seja, a nível molecular. Vejamos brevemente do que se trata com a ajuda da Figura 5.

Em muitos campos da tecnologia a miniaturização dos componentes da aparelhagem tornou-se uma necessidade cada vez mais premente. Isto é particularmente válido para as memórias dos calculadores electrónicos, com o fim de obter aparelhos cada vez mais pequenos e ao mesmo tempo cada vez mais potentes. De grande interesse são as estruturas possuindo as dimensões de 1 a 100 nanómetros. Para a produção de componentes miniaturizados, até ao momento seguiu-se a abordagem "de cima abaixo" (top dow), trabalhando os materiais macroscópicos com técnicas especiais como a litografia. Mas, os limites desta

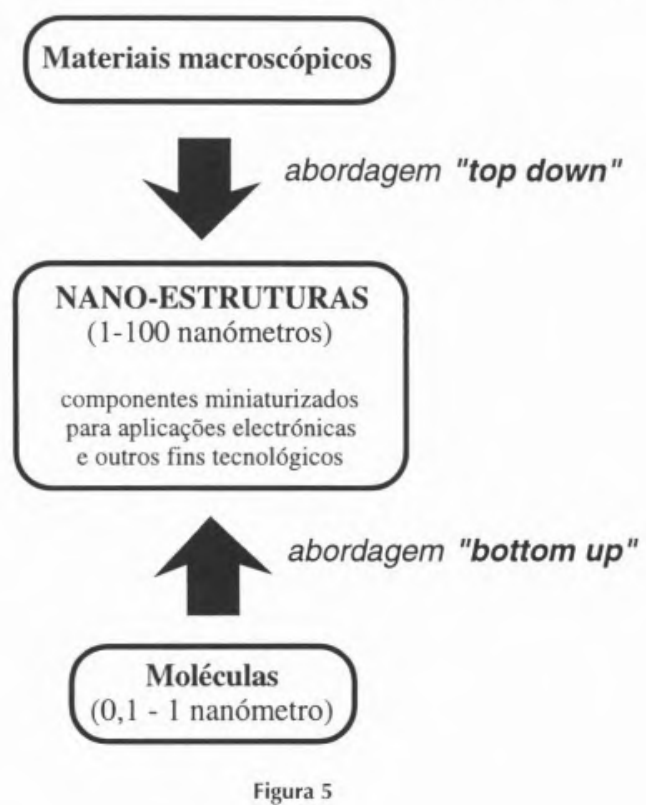


abordagem foram já atingidos. Pode ser vantajosa, então, especialmente para obter estruturas ainda mais pequenas, a abordagem "de baixo acima" (bottom up), através duma montagem molécula a molécula. Trata-se de uma verdadeira e autêntica engenharia a nível molecular.

O ambicioso projecto dos químicos é o de construir mecanismos, dispositivos e máquinas ao nível molecular, capazes de efectuar funções úteis. Para perceber o que significa mecanismo ou máquina a nível molecular e qual a lógica que os químicos pretendem seguir para construir estes dispositivos, pode tornar-se útil uma analogia muito simples. Para construir um aparelho do mundo macroscópico (por exemplo, um secador), o engenheiro constrói componentes (um interruptor, um ventilador, uma resistência) cada um deles apto a desempenhar uma acção específica. Seguidamente, os componentes são montados num determinado modo obtendo-se um aparelho que, alimentado a energia eléctrica, executa uma função útil. O químico do futuro procederá de modo idêntico, não a nível macroscópico, mas sim a nível molecular. Antes de mais trata-se de construir moléculas capazes de executar acções específicas (por exemplo, absorver um fotão, transferir um electrão), depois montá-las em estruturas supramoleculares organizadas, de modo a que o resultado coordenado das acções dos componentes possa dar lugar a uma função útil. Estes dispositivos ao nível molecular funcionam fazendo mover electrões, átomos, ou inteiras moléculas. No nosso laboratório, já construímos componentes destas máquinas moleculares, como fios moleculares capazes de conduzir electrões ou energia electrónica, e interruptores moleculares capazes de permitir ou impedir a passagem destes fluxos.

Como sucede com os dispositivos e as máquinas do mundo macroscópico, também para fazer funcionar os dispositivos e máquinas moleculares se torna necessário fornecer energia e dispôr de sinais que metam em comunicação a máquina com o operador.

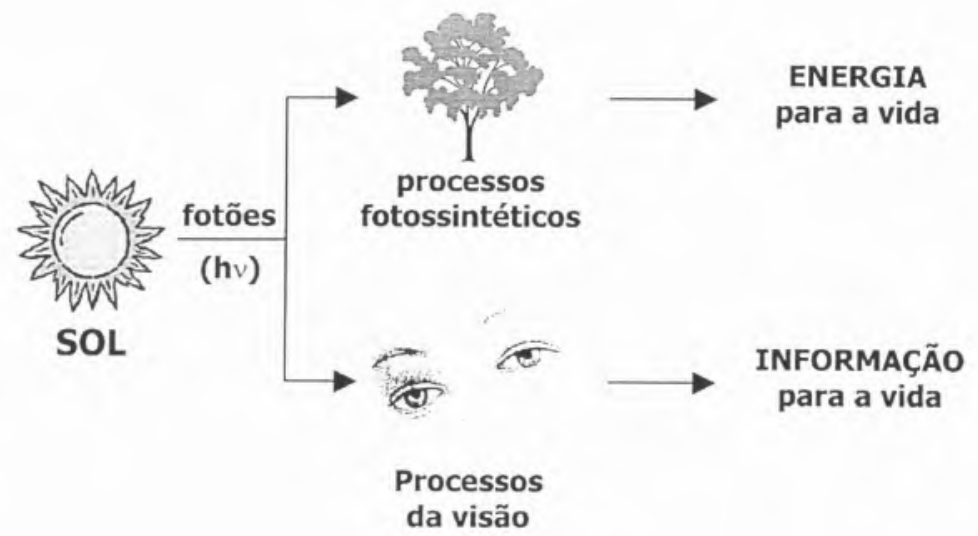

Figura 6

Este duplo problema, para as máquinas moleculares, pode ser resolvido com a luz. A luz, como é bem conhecido, é feita de fotões e o fotão na sua interacção com a matéria pode funcionar como "quantum de energia" ou como "elemento de informação". Isto acontece normalmente na natureza, onde a luz solar é utilizada no processo fotossintético para obter os produtos agrícolas (ou seja energia), e nos processos relacionados com a visão para obter informação sobre o mundo que nos rodeia (Figura 6).

Portanto, também em sistemas artificiais a interacção entre luz e matéria pode ser utilizada para obter energia ou elaborar informação. Os estudos a este respeito encontram-se numa fase muito adiantada.

\section{MÁQUINAS MOLECULARES}

Enquanto já se fantasiam uma série de máquinas moleculares que num futuro não longínquo deverão reparar células doentes, decompor substâncias nocivas, elaborar informações, etc., começam a surgir os primeiros protótipos de rudimentares máquinas moleculares. Sem me demorar sobre o aspecto mais científico. demasiado especializado, gostaria de vos mostrar alguns exemplos simples. Foram já construídas moléculas, como a representada na Figura 7, que por acção de um fotão se fecham como uma pinça e portanto podem agarrar átomos ou pequenas moléculas. Outras máquinas moleculares simples são constituídas por sistemas chamados rotaxanos e catenanos. Alguns exemplos são mostrados na Figura 8 . No primeiro sistema, graças à aç̧ão de um fotão ou de um electrão podem-se desenfiar e reenfiar os dois componentes moleculares, aquele em forma de fio naquele em forma de anel. No segundo sistema (catenano), sempre graças à acção de um fotão ou de um electrão pode fazer-se girar um dos dois anéis em relação ao outro. $\mathrm{O}$ terceiro sistema é constituído por uma molécula em forma de anel, enfiada numa molécula filiforme que contém dois centros distintos: com o impulso de um fotão ou de um electrão, o anel pode deslocar-se de um local para o outro. É um sistema claramente análogo a um ábaco. O extraordinário é que se trata de um ábaco com um comprimento de poucos bilionésimo de metro e que pode ser posto em acção pela luz.

Mas há mais. Uma vez que estes movimentos correspondem a uma lógica binária, alguns destes sistemas são capazes de efectuar operações lógicas, ou seja, são capazes de ter um sinal de saída (que pode ser, por exemplo, um sinal de fluorescência) modulado por sinais de entrada (que podem ser fotões, electrões, ácidos, bases). Recentemente demonstrámos que o rotaxano representado na Figu- 

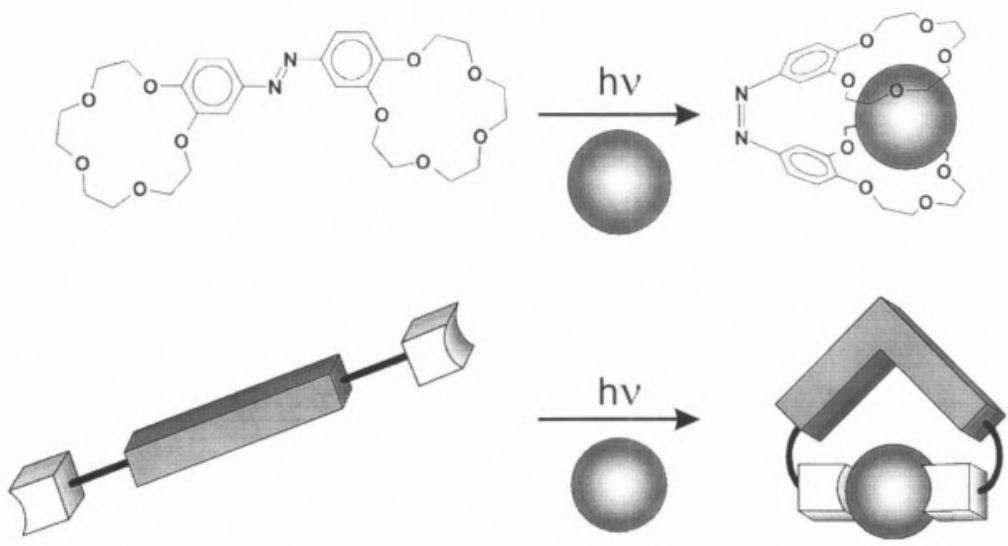

Figura 7

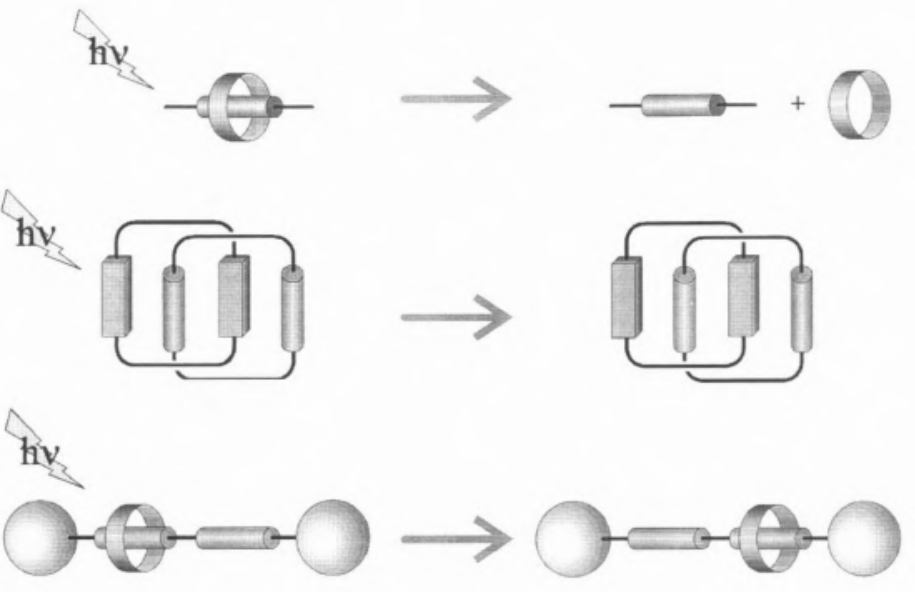

Figura 8

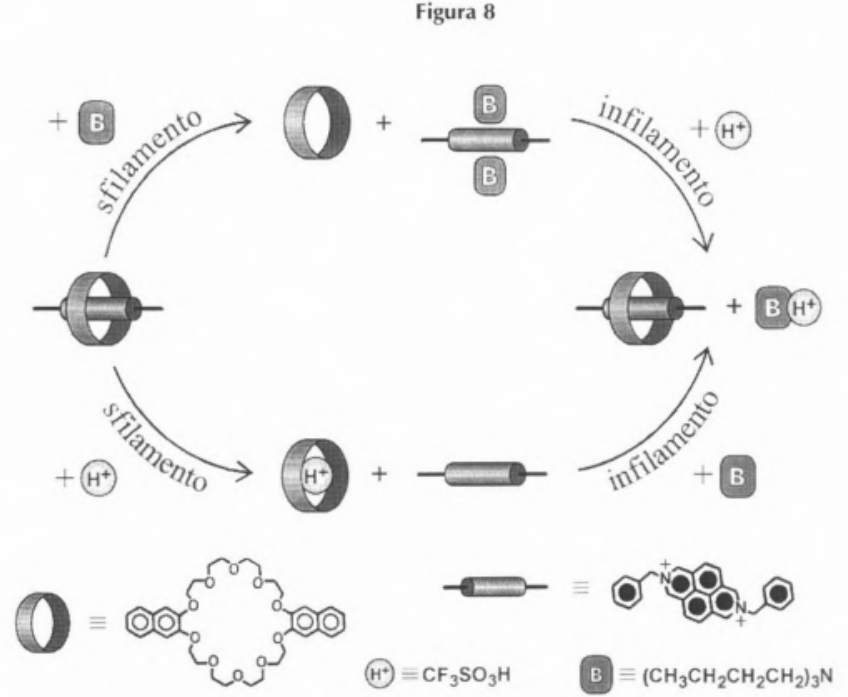

Figura 9 ra 9 pode efectuar uma operação lógica complexa como a designada, em gíria, pela sigla XOR. Por razões óbvias não posso descrever em detalhe como funciona este dispositivo molecular. Gostaria apenas de fazer notar que alguns cientistas vêem nestas pesquisas os primeiros passos num caminho que poderá conduzir à construção de uma nova geração de computadores que, baseando-se em elementos de memória com a dimensão do nanómetro, poderão oferecer rendimentos muito superiores aos dos calculadores actualmente em uso.

\section{CONCLUSÕES}

Antes de concluir, gostaria de regressar brevemente a alguns problemas de carácter geral.

Desejo sublinhar antes de mais que é urgente reunificar cultura humanística e cultura científica, reconciliar as pessoas com a ciência, e em particular com a química. Sem uma consciência científica de base, a sociedade tecnológica em que vivemos não pode funcionar de um modo democrático.

Um segundo ponto. Hoje existe uma certa tendência a privilegiar a investigação aplicada em relação à fundamental. Mas a história da ciência ensina-nos que é a investigação científica fundamental aquela que mais contribui para o progresso da humanidade. Poder-se-ia dar tantos exemplos. Limito-me a mencionar uma anedota em que se conta que, no século passado, quando o Primeiro Ministro inglês Gladstone foi visitar o laboratório do famoso cientista Faraday, perguntou se aquela substância esotérica, chamada electricidade, sobre a qual Faraday estava fazendo experiências, teria alguma vez uma qualquer aplicação prática. A resposta de Faraday foi lapidar: "Esta substância que Vossa Excelência chama esotérica, senhor Ministro, um dia pagará imposto."

Um terceiro ponto. Nos países desenvolvidos, até agora foi privilegiada a dita "grande ciência", ou seja os megaprojectos de física nuclear e 
de exploração do espaço. No entanto, foram descuradas as pesquisas em campos, como a química, onde se trabalha no âmbito de projectos baseados na criatividade dos investigadores e caracterizados por proveitos benéficos em relação às necessidades da humanidade. Estiveram frequentemente razões militares na base das escolhas feitas no passado. Agora, porém, apesar das restrições orçamentais, é urgente rever a política de distribuição dos recursos para a investigação científica.

As pessoas menos familiarizadas com a ciência podem colocar, muito justamente, uma pergunta: até quando haverá progresso científico? Conta-se que na América em 1865. no tempo de Abraham Lincoln, o chefe do gabinete de patentes escreveu ao Governo uma nota informativa na qual sustentava que, dada a grande velocidade a que se davam as descobertas naquele período, o gabinete fecharia em poucos anos porque tudo o que fosse necessário descobrir, em poucos anos, de facto, seria descoberto.

Presentemente, pelo contrário, encontra-se difundida a ideia que cada descoberta científica gera mais perguntas que aquelas a que dá resposta. Conceito que já tinha sido muito bem expresso, no longínquo 1791, por Joseph Priestley, o primeiro cientista que investigou a fotossíntese: "Quanto maior o círculo de luz, maior a margem de obscuridade em que o círculo se encontra confinado. Mas, apesar disso, quanto mais luz fizermos, mais gratos devemos estar, porque isso significa que temos um maior horizonte a contemplar. Com o tempo os confins da luz estender-se-ão ainda mais; e dado que a Natureza divina é infinita, podemos esperar um progresso sem fim nas nossas investigações sobre a mesma: uma perspectiva sublime e simultaneamente gloriosa".

Belo, não é verdade? Atenção, porém. Isto não quer dizer que, quem faz investigação científica se pode deixar ficar isolado numa mais ou menos alta torre de marfim, a contemplar a beleza das suas pesquisas. Os cientis- tas, mais ainda que os restantes cidadãos, devem estar bem conscientes que a ciência se move mais rapidamente que as nossas capacidades para perceber as suas implicaçōes, deixando no seu rasto um labirinto de problemas éticos e morais. Leonardo da Vinci, numa carta ao Duque de Milão, comentando a sua ideia de construir um submergível, escreveu: "Eu não descrevo o meu método para permanecer debaixo de água por muito tempo, porque os homens com a sua natural maldade o usariam para destruir a quilha dos barcos e afundá-los com a sua tripulação.". Infelizmente muitos cientistas não se colocam problemas do género e usam a sua criatividade para inventar armamentos cada vez mais mortíferos. Algumas semanas atrás os jornais deram-nos a saber que o último destes armamentos é um laser químico, o "Mid Infra Red Advanced Chemical Laser", que com muito mau gosto vem designado com a sigla MIRACL. Todos sabemos que a empresa científica é de per si ambígua. O laser pode ser utilizado em operações cirúrgicas ou, como é o caso, para construir armas mortíferas. Com um computador pode-se controlar a sala de reanimação de um hospital ou as baterias de mísseis de um cruzador. E se é verdade que não se pode condenar os cientistas por terem inventado o computador, também é verdade que se pode condená-los se agora não lutarem para que hajam mais hospitais e menos cruzadores.

É talvez chegada a hora em que o homem, após ter demonstrado com a ciência de saber fazer tudo ou quase tudo, demonstrar também saber reflectir e, se necessário, saber parar. Se por um lado é difícil, e talvez também ilógico, colocar limites à pesquisa científica, cuja tarefa é descobrir toda a verdade, surge não só como lógico, mas necessário, impedir a concretização de tecnologias contrárias ao interesse do homem.

A ciência e a tecnologia devem ser partilhadas por todo o género humano, como o ar e a água, e devem ser usadas para o progresso da humanidade e não para a sua ruína, para o bem de todos e não para o privilégio de alguns, para conservar os recursos naturais e não para destruí-los, para a paz e não para a guerra. Quer-se um grande sentido de responsabilidade, pois é necessário atingir rapidamente um grau de maturidade moral e política muito mais elevado que o actual.

Gostaria de fazer uma última reflexão. Alguém poderia perguntar-me: o que sente um químico ao sintetizar uma nova molécula, ou ao inventar uma nova máquina molecular? De uma forma mais geral, o que sente um cientista no seu trabalho de investigação? Na ciência, como em toda a actividade "criativa", podem-se tomar duas atitudes extremas: o orgulho de ter dado ao mundo algo que não existia ou de se ter descoberto algo que não se conhecia, ou então a humildade de quem, consciente da sua própria pequenez, agradece a Deus por o ter usado como seu instrumento para ir revelando a beleza da criação. Newton, face às suas memoráveis descobertas dizia: "Sinto-me como uma criança que brincando à beira-mar se diverte a apanhar ora uma pedrinha mais macia, ora uma conchinha mais brilhante do habitual, enquanto o oceano ilimitado da verdade se estende inexplorado diante mim". Também eu, no meu trabalho, experimento esta sensação. E partilho também dos sentimentos do geneticista americano Francis Collins que recentemente disse: "Sempre que percebemos algo mais sobre o genoma humano, eu experimento um sentimento de profundo respeito, ao pensar que a humanidade fica a conhecer algo que antes só Deus conhecia."

Tradução de Maria João Seixas de Melo Revisāo de F. J. Pina e A. J. Parola Grupo de Fotoquímica da FCT-UNL

Discurso inaugural do ano académico 1997-1998 Universidade de Bolonha, Itália.

** Dipartimento di Chimica "G. Ciamician". Università degli Studi di Bologna, Itália.

1) refere-se a ltália, mas a observação vale também para Portugal.

2) Em Português traduzido com o título de "O sistema Periódico", ed. Gradiva. 


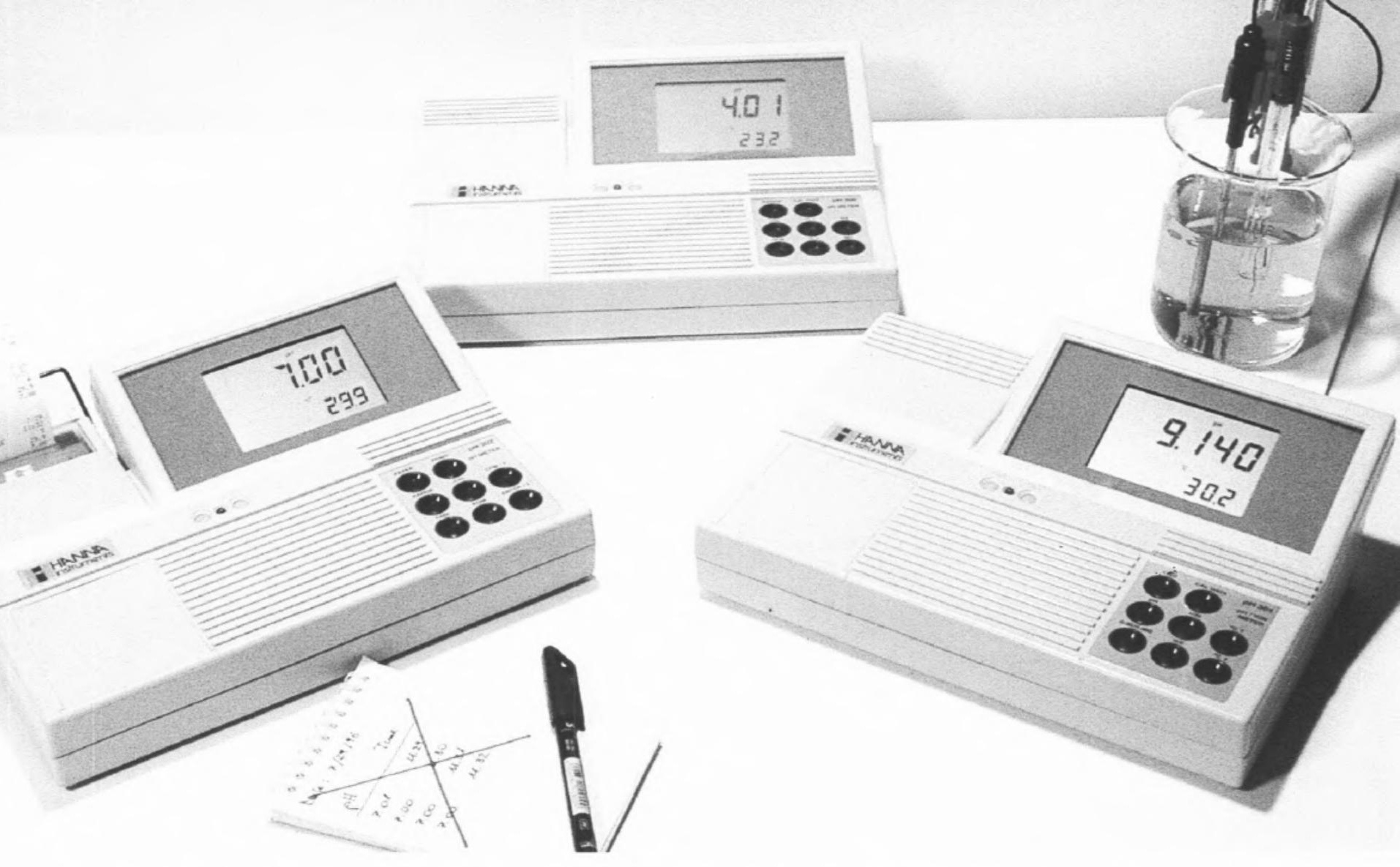

\section{MEDIDORES DE $\mathrm{pH}$ DE ALTA TECNOLOGIA FÁCEIS DE USAR E ECONÓMICOS}

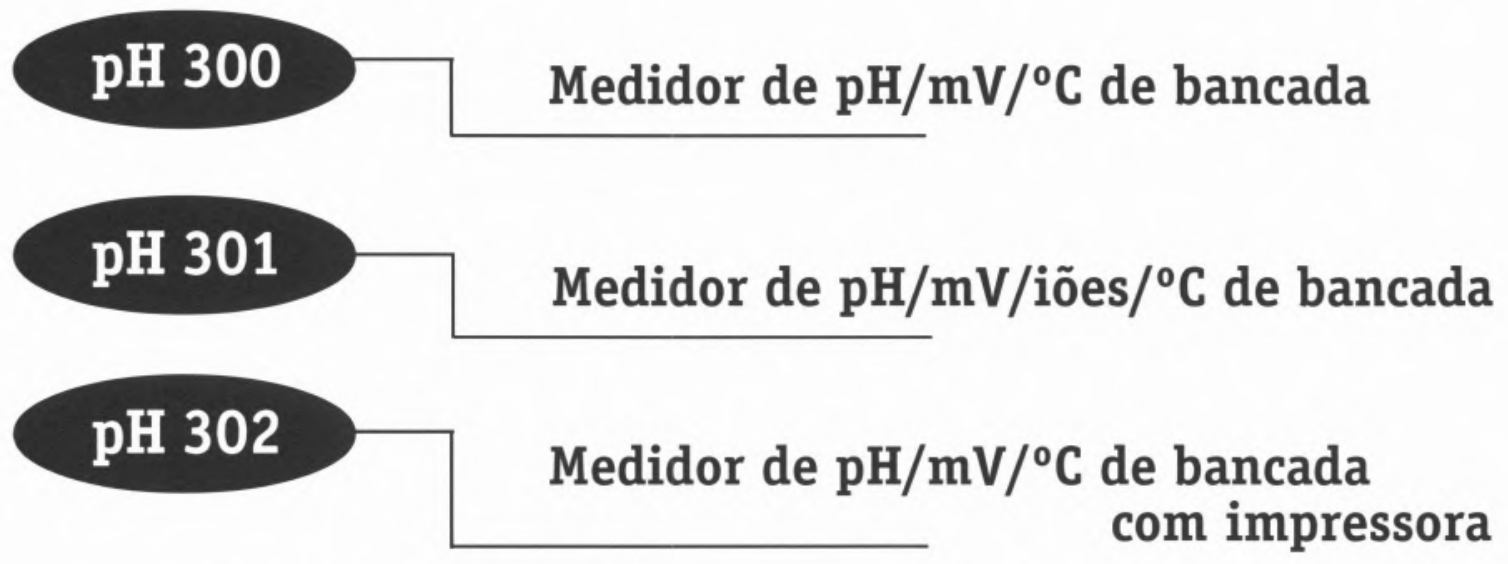

De acordo com as GLP

\section{From

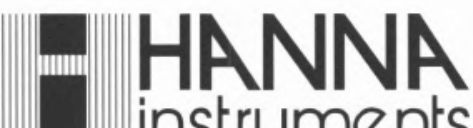 \\ instruments ISO 9000 CERTIFIED \\ ... of course}

Dos 700 funcionários do grupo Hanna, 130 estão ao seu serviço em Portugal. 